\title{
Relationship of socio-economic status with nutritional status among the elderly in a rural community of Bangladesh
}

\author{
SUMON CHANDRA DEBNATH ${ }^{A-F}$ \\ National Institute of Preventive and Social Medicine (NIPSOM), Mohakhali, Dhaka-1212, Bangladesh
}

A - Study Design, B - Data Collection, C - Statistical Analysis, D - Data Interpretation, E - Manuscript Preparation, F - Literature Search, G - Funds Collection

Summary Background. A poor nutritional status is more frequent in developing and low-income countries. In these countries, the impact of socio-economic factors may be more pronounced, because of high inequities and limited access to health and social services. In the elderly population, underweight and overweight are important issues that need to be considered.

Objectives. The purpose of this study was to assess the nutritional status with different socio-economic parameters among rural elderly people.

Material and methods. A cross-sectional study was carried out among 330 elderly people ( $\geq 60$ years) living in a rural community of Bangladesh. Nutritional status was assessed by the WHO referred Body Mass Index (BMI). 15 respondents were excluded from BMI measurement. Malnutrition was considered as both underweight and overweight.

Results. More than half $(59.7 \%)$ of the study participants were in the age group from 60 to 69 years. Females $(56.1 \%)$ were predominant over males (43.9\%). BMI analysis revealed that about half (48.3\%) of the study participants were underweight and only $7.0 \%$ were overweight, with $44.7 \%$ being normally nourished. The prevalence of underweight was $50.0 \%$ in males and $46.9 \%$ in females; hence, overweight affected $2.1 \%$ of males and $10.9 \%$ of females. Female gender and higher age were significantly associated $(p<0.05)$ with the poor nutritional status of the elderly.

Conclusions. This study shows a high prevalence of underweight among elderly people in rural Bangladesh. In order to reduce the proportion of the undernourished, it is important to address this subset of the population.

Key words: nutritional status, malnutrition, elderly, Socio-Economic Status (SES).

Debnath SC. Relationship of socio-economic status with nutritional status among the elderly in a rural community of Bangladesh. Fam Med Prim Care Rev 2017; 19(2): 104-109, doi: https://doi.org/10.5114/fmpcr.2017.67862.

\section{Background}

The older population is itself aging. Population aging is taking place in nearly all the countries of the world [1], and the rise will, both in relative and absolute terms, be much more intense in low-income than in high-income regions of the world [2]. The proportion of the world's population aged 60 years or over increased from $8 \%$ in 1950 to $12 \%$ in 2013 . It will increase more rapidly in the next four decades to reach $21 \%$ in 2050 [1]. By the end of this century, however, it is projected that this group will constitute almost $26 \%$ of the total population of Bangladesh [3]. Despite this, the issue of aging is not a primary concern for policy makers and planners in Bangladesh. At the primary or at other levels, the necessities of elderly health care are rarely addressed. There are no separate healthcare facilities for older adults, and so far no comprehensive health policy exists for this group of people [4]. Numerous factors can lead to malnutrition among older persons, including physical, medical, psychiatric, social and economic factors. In the majority of cases, these factors are related to each other. The most significant influences of malnourishment are poor diet and disease, which are connected to access to food and are influenced by socio-economic status [5]. Social factors, e.g. lack of social support, having a limited social network or being socially isolated, are also associated with nutritional status in elderly individuals $[6,7]$. In the elderly population, underweight and overweight are important issues to be considered [8]. There are different procedures to evaluate the nutritional status in the elderly, and Body Mass Index (BMI) is commonly used in epidemiological studies [8-10], having the advantage of being simple, easy to apply and noninvasive [10]. There are few studies that address the nutritional status of the elderly population in the rural community of Bangladesh $[4,11]$. Research and public health activities in Bangladesh have so far focused largely on nutritional aspects related to children and women of reproductive age $[11,12]$. Studies on the elderly aged 60 years and above living in the rural community have demonstrated that factors related to nutritional status vary [4], highlighting the need for more studies on the socio-economic factors associated with underweight and overweight in the oldest of this group [4, 12].

\section{Objectives}

The purpose of this study was to assess the nutritional status that prevails among rural elderly and the extent of malnutrition with different socio-economic parameters.

\section{Material and methods}

\section{Study population}

This cross-sectional study was carried out among elderly people ( $\geq 60$ years) residing in the Deora village of Barura Upazila under the Comilla District of Bangladesh. The demographic data and profile of the population of the village were studied, 
and a household list was collected from the Deora Union Parishad after being granted due permission from the authorities concerned. The Deora village has a population of approximately 10,343 people distributed throughout 1,512 households.

\section{Sample size and sampling}

The sample size calculation was performed considering a confidence level of $95 \%, Z=1.96, d=0.05$, prevalence of undernourished as $26 \%$ [13], and by using the formula $n=\left[Z^{2} p q /\right.$ $\left./ d^{2}\right]$, the sample size was calculated as 330 . Cluster sampling was used as a sampling method. A total of 8 clusters were designated by geographical location, and 42 elderly persons who met the inclusion criteria were selected from each cluster by simple random sampling from a pool of 1,443 elderly. A total of 330 elderly people aged 60 years and above were included in the study. The inclusion criteria were: 1 ) all the individuals were 60 years of age or older; 2 ) all were permanent residents of this village; 3 ) all were physically residing there during the period of the study. The criteria for exclusion were: 1 ) being under 60 years of age; 2 ) elderly people from the urban area present in the village during the study period; 3 ) being blind and/or deaf; 4) a severe mental disorder or physically handicapped person; 5) refusing to participate in this study.

\section{Data collection}

The study was conducted during the period from January to December 2015. The elderly population was identified from a listed household based on a house-to-house visit. A pre-test was done among 30 elderly people in another rural area of the Comilla district rather than the actual study area (Deora village). Data was collected by using a pre-tested questionnaire, and a checklist was used to record the weight and height of the study participants. The socio-economic characteristic of subjects (age, gender, family income, educational status, occupation, family size) was confirmed through face-to-face interviews. Height and weight were recorded after each interview. Privacy was preserved during data collection, and the confidentiality of data was strictly kept.

\section{Nutritional assessment}

Several methods were suggested for assessing the nutritional status of the elderly. The World Health Organization recommended Body Mass Index (BMI) is one of the reliable, feasible and non-invasive procedures for evaluating nutritional status in elderly people [14]. Anthropometric measurement was carried out for height and weight. Weight and height were measured by using a standardized weighing machine and stadiometer, respectively. Body weight was measured without shoes and with light clothing using a Seca scale (Seca, Hamburg, Germany) to the nearest $0.1 \mathrm{~kg}$. Height was also measured, without shoes, using a stadiometer (Seca, Hamburg, Germany) to the nearest $0.1 \mathrm{~cm}$. BMI was calculated as weight (kilograms) divided by height (meters) squared and classified according to World Health Organization categories [14].

\section{Statistical analysis}

SPSS software (version 20.0, Chicago, IL, USA) was used for statistical analysis of the data. The normality of the data was evaluated using the Shapiro-Wilk test. Continuous variables as mean \pm standard deviation (SD) and qualitative data were presented as frequency (percentage). Continuous variables: Age and Income were not normally distributed; therefore, median and range were used for these variables. The chi-square test was used to determine the relationship between two categorical variables. A $p$-value less than 0.05 was considered as significant.

\section{Ethical issues}

Ethical clearance was granted by the Institutional Review Board (IRB) of the National Institute of Preventive \& Social Medicine (NIPSOM), Dhaka, Bangladesh. Informed consent was granted by the participants before commencing the study.

\section{Results}

The socio-demographic characteristics of the respondents are summarized in Table 1 . The majority of the respondents (59.7\%) were young-old, i.e. between 60 to 69 years of age, and the median age was 66 years, with minimum age 60 years and maximum of 100 years of age (Table 1$)$. Most were female (56.1\%), a large proportion were married $(66.4 \%)$, i.e. living with their spouse, and a majority were Muslim (54.8\%). Regarding education, most of the respondents (84.9\%) were illiterate, and a majority (82.1\%) were unemployed (Table 1$)$. As for monthly family income, about half $(48.2 \%)$ of the respondents were in the income group of 10,001-20,000 BDT, and the median income was $19,000 \mathrm{BDT}$, with a minimum income of $400 \mathrm{BDT}$ and a maximum income of 80,000 BDT (Table 1).

The nutritional status of the respondents was assessed according to the WHO recommended Body Mass Index (BMI). The BMI cut-off score of $18.5-24.99 \mathrm{~kg} / \mathrm{m}^{2}$ was considered 'Normal', $\geq 25.00 \mathrm{~kg} / \mathrm{m}^{2}$ was considered as 'Overweight', and $<18.50 \mathrm{~kg} / \mathrm{m}^{2}$ was considered as 'Underweight'. Among the 330 respondents, 15 respondents were excluded (due to difficulty in measuring weight) from BMI measurement; therefore, 315 respondents were included in the BMI measurement. Out of 315 respondents, about half (48.3\%) had a $\mathrm{BMI}<18.50 \mathrm{~kg} / \mathrm{m}^{2}$, $44.7 \%$ had a BMI $18.5-24.99 \mathrm{~kg} / \mathrm{m}^{2}$ and only $7.0 \%$ had a BMI $\geq 25.00 \mathrm{~kg} / \mathrm{m}^{2}$. The mean BMI was $19.21 \pm 3.45 \mathrm{~kg} / \mathrm{m}^{2}$ with a minimum of $12.23 \mathrm{~kg} / \mathrm{m}^{2}$ and a maximum of $31.39 \mathrm{~kg} / \mathrm{m}^{2}$ (Table 2). Among 140 male respondents, half were underweight, only $2.1 \%$ were overweight, and $47.9 \%$ were normally nourished. Among 175 female respondents, about half (46.9\%) were underweight, $42.3 \%$ were normally nourished, and a good number (10.8\%) were overweight (Table 2).

\begin{tabular}{|c|c|c|c|c|c|c|}
\hline \multirow{3}{*}{ Variables } & \multicolumn{4}{|l|}{ Gender } & & \\
\hline & \multicolumn{2}{|c|}{ Male $(n=145)$} & \multicolumn{2}{|c|}{ Female $(n=185)$} & \multicolumn{2}{|l|}{ Total $(n=330)$} \\
\hline & $\bar{n}$ & $\%$ & $n$ & $\%$ & $\bar{n}$ & $\%$ \\
\hline \multicolumn{7}{|l|}{ Age Group } \\
\hline Young-old (60-69 years) & 84 & 42.6 & 113 & 57.4 & 197 & 59.7 \\
\hline Oldest-old ( $70-79$ years) & 34 & 43.6 & 44 & 56.4 & 78 & 23.6 \\
\hline Very old ( $\geq 80$ years) & 27 & 49.1 & 28 & 50.9 & 55 & 16.7 \\
\hline Median (Min-Max) Age & $66(60-97)$ & & $65(60-100)$ & & $66(60-100)$ & \\
\hline \multicolumn{7}{|l|}{ Marital status } \\
\hline Married & 133 & 60.7 & 86 & 39.3 & 219 & 66.4 \\
\hline Single (widow/widower) & 12 & 10.8 & 99 & 89.2 & 111 & 33.6 \\
\hline
\end{tabular}




\begin{tabular}{|c|c|c|c|c|c|c|}
\hline \multirow{3}{*}{ Variables } & \multicolumn{4}{|c|}{ Gender } & & \\
\hline & \multicolumn{2}{|c|}{ Male $(n=145)$} & \multicolumn{2}{|c|}{ Female $(n=185)$} & \multicolumn{2}{|c|}{ Total $(n=330)$} \\
\hline & $n$ & $\%$ & $n$ & $\%$ & $n$ & $\%$ \\
\hline \multicolumn{7}{|l|}{ Educational status } \\
\hline No education & 105 & 37.6 & 174 & 62.4 & 279 & 84.5 \\
\hline Primary & 17 & 65.4 & 9 & 34.6 & 26 & 7.9 \\
\hline Above primary & 23 & 92.0 & 2 & 8.0 & 25 & 7.6 \\
\hline \multicolumn{7}{|l|}{ Employment status } \\
\hline Unemployed & 87 & 32.1 & 184 & 67.9 & 271 & 82.1 \\
\hline Employed & 58 & 98.3 & 1 & 1.7 & 59 & 17.9 \\
\hline \multicolumn{7}{|l|}{ Family type } \\
\hline Single & 22 & 36.1 & 39 & 63.9 & 61 & 18.5 \\
\hline Joint & 123 & 45.7 & 146 & 54.3 & 269 & 81.5 \\
\hline \multicolumn{7}{|l|}{ Living Arrangement } \\
\hline Live with children & 120 & 44.1 & 152 & 55.9 & 272 & 82.4 \\
\hline Live with spouse only & 25 & 64.1 & 14 & 35.9 & 39 & 11.8 \\
\hline Alone & 0 & 0.0 & 19 & 100.0 & 19 & 5.8 \\
\hline \multicolumn{7}{|l|}{ Monthly family income } \\
\hline$\leq 10,000 \mathrm{BDT}$ & 14 & 30.4 & 32 & 69.6 & 46 & 13.9 \\
\hline 10,001 to 20,000 BDT & 77 & 48.4 & 82 & 51.6 & 159 & 48.2 \\
\hline$\geq 20,001$ BDT & 54 & 43.2 & 71 & 56.8 & 125 & 37.9 \\
\hline Median (Min-Max) Income & \multicolumn{6}{|c|}{$20,000(7000-80,000) 18,000(400-80,000) 19,000(400-80,000)$} \\
\hline
\end{tabular}

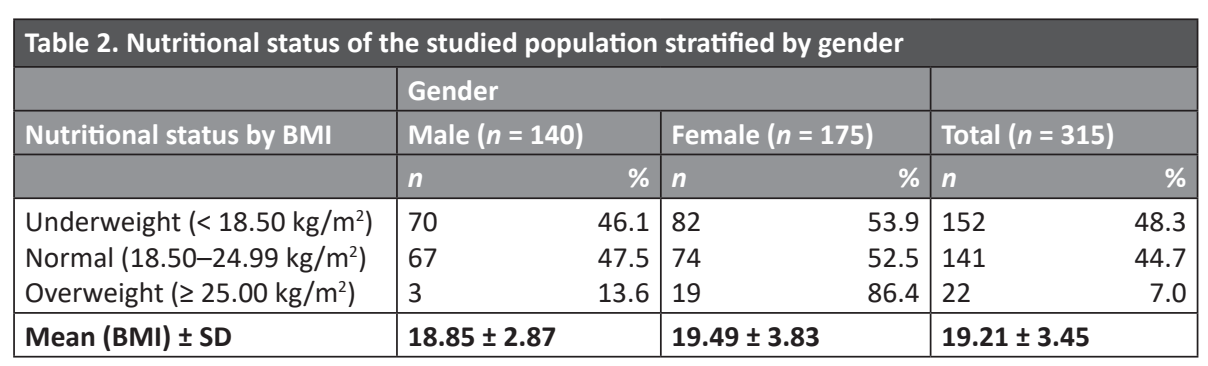

\begin{tabular}{|c|c|c|c|c|c|c|c|c|}
\hline \multirow{3}{*}{ Socio-demographic variables } & \multicolumn{6}{|c|}{ Nutritional status } & \multirow{3}{*}{ Total } & \multirow{3}{*}{$p$} \\
\hline & \multicolumn{2}{|c|}{ Underweight } & \multicolumn{2}{|c|}{ Normal } & \multicolumn{2}{|c|}{ Overweight } & & \\
\hline & $n$ & $\%$ & $n$ & $\%$ & $n$ & $\%$ & & \\
\hline \multicolumn{9}{|l|}{ Age class } \\
\hline Young-old & 88 & 45.2 & 89 & 45.6 & 18 & 9.2 & 195 & \multirow{3}{*}{$0.029 *$} \\
\hline Oldest-old & 33 & 44.6 & 38 & 51.4 & 3 & 4.1 & 74 & \\
\hline Very old & 31 & 67.4 & 14 & 30.4 & 1 & 2.2 & 46 & \\
\hline \multicolumn{9}{|l|}{ Gender } \\
\hline Male & 70 & 50.0 & 67 & 47.9 & 3 & 2.1 & 140 & \multirow[t]{2}{*}{$0.010^{*}$} \\
\hline Female & 82 & 46.9 & 74 & 42.3 & 19 & 10.9 & 175 & \\
\hline \multicolumn{9}{|l|}{ Marital status } \\
\hline Married & 95 & 44.4 & 102 & 47.7 & 17 & 7.9 & 214 & \multirow[t]{2}{*}{0.123} \\
\hline Single & 57 & 56.4 & 39 & 38.6 & 5 & 5.0 & 101 & \\
\hline \multicolumn{9}{|l|}{ Educational status } \\
\hline Illiterate & 131 & 49.4 & 117 & 44.2 & 17 & 6.4 & 265 & \multirow{3}{*}{0.051} \\
\hline Primary & 15 & 60.0 & 9 & 36.0 & 1 & 4.0 & 25 & \\
\hline Above primary & 6 & 24.0 & 15 & 60.0 & 4 & 16.0 & 25 & \\
\hline \multicolumn{9}{|l|}{ Employment status } \\
\hline Unemployed & 120 & 46.9 & 115 & 44.9 & 21 & 8.2 & 256 & \multirow[t]{2}{*}{0.178} \\
\hline Employed & 32 & 54.2 & 26 & 44.1 & 1 & 1.7 & 59 & \\
\hline \multicolumn{9}{|l|}{ Family types } \\
\hline Single & 30 & 52.6 & 22 & 38.6 & 5 & 8.8 & 57 & \multirow[t]{2}{*}{0.553} \\
\hline Joint & 122 & 47.3 & 119 & 46.1 & 17 & 6.6 & 258 & \\
\hline \multicolumn{9}{|l|}{ Living Arrangement } \\
\hline Live with children & 122 & 46.9 & 118 & 45.4 & 20 & 7.7 & 260 & \multirow{3}{*}{0.779} \\
\hline Live with spouse only & 19 & 51.4 & 16 & 43.2 & 2 & 5.4 & 37 & \\
\hline Alone & 11 & 61.1 & 7 & 38.9 & 0 & 0.0 & 18 & \\
\hline
\end{tabular}




\begin{tabular}{|c|c|c|c|c|c|c|c|c|}
\hline \multirow{3}{*}{ Socio-demographic variables } & \multicolumn{6}{|c|}{ Nutritional status } & \multirow{3}{*}{ Total } & \multirow{3}{*}{$p$} \\
\hline & \multicolumn{2}{|c|}{ Underweight } & \multicolumn{2}{|c|}{ Normal } & \multicolumn{2}{|c|}{ Overweight } & & \\
\hline & $n$ & $\%$ & $n$ & $\%$ & $n$ & $\%$ & & \\
\hline \multicolumn{9}{|c|}{ Monthly family income (taka/month) } \\
\hline Up to 10,000 & 23 & 53.5 & 16 & 37.2 & 4 & 9.3 & 43 & \multirow{3}{*}{0.058} \\
\hline $10,001-20,000$ & 81 & 52.3 & 69 & 44.5 & 5 & 3.2 & 155 & \\
\hline 20,001 and above & 48 & 41.0 & 56 & 47.9 & 13 & 11.1 & 117 & \\
\hline
\end{tabular}

* Significance at a level of $0.05(p<0.05)$.

Underweight was the highest $(67.4 \%)$ in the age group of $\geq 80$ years, i.e. very old elderly, and the lowest (44.6\%) was in the oldest-old category. Normal BMI was the highest (51.4\%) among the oldest-old elderly; on the others hand, the very old elderly was the lowest (30.4\%). In the overweight category, the maximum proportions (9.2\%) were the young-old as opposed to only $2.2 \%$ with the very old. There was a significant relationship between age and nutritional status $(p<0.05)$. Nutritional status deteriorates with increased age (Table 3). The percentage of underweight was higher in males $(50.0 \%)$ than females $(46.9 \%)$. On the other hand, females $(10.9 \%)$ were more overweight than males $(2.1 \%)$, and this association was statistically significant $(p<0.05)$ (Table 3). More than half $(56.4 \%)$ of the single (widow/ /widower) elderly were underweight, whereas $44.4 \%$ of the married elderly were underweight. No significant $(p>0.05)$ association was found between marital status and level of nutritional status (Table 3 ). About two-thirds $(60.0 \%)$ of elderly that completed primary education was suffering from undernutrition, whereas about half $(49.4 \%)$ of the illiterate elderly were suffering from undernutrition. It was found that maximum $(16.0 \%)$ above primary elderly were suffering from overnutrition than illiterate (6.4\%) and primary (4.4\%). The chi-exact test revealed that there was no relationship between educational status and the level of nutritional status $(p>0.05)$ (Table 3$)$. The percentage of underweight was higher among employed $(54.2 \%)$ than unemployed (46.9\%). On the other hand, the percentage of overweight was higher among unemployed elderly (8.2\%) than employed elderly (1.7\%). However, the proportion of normal BMI was almost similar in both unemployed and employed respondents. There was no significant $(p>0.05)$ relationship of current occupation with the level of nutritional status (Table 3). Underweight was almost equal in both single and joint families $(52.6 \%$ and $47.3 \%$, respectively). On the other hand, respondents who lived in a joint family were more normally nourished $(46.1 \%)$ than those in a single family $(38.6 \%)$. These differences were not statistically significant $(p>0.05)$ (Table 3$)$. Living arrangements in the male group were higher than the female group in all nutritional status categories. Living arrangements had no significant influence over malnutrition in the rural elderly $(p>0.05$ ) (Table 3 ).

The proportion of underweight was more $(53.5 \%)$ among those with monthly family incomes below 10,000 , whereas it was less (41.0\%) in the 20,001 and above group. However, this was opposite in the case of overweight, where the maximum (11.1\%) were in the 20,001 and above group. No statistically significant $(p>0.05)$ association was found between monthly family income and the level of nutritional status (Table 3 ).

\section{Discussion}

In this study, a high percent of the elderly were underweight (48.3\%), and only $7.0 \%$ were overweight. The above findings of this study are in accordance with previous studies in Bangladesh $[15,16]$. A rural-based cross-sectional study conducted by Alam et al. [16] in Bangladesh also found a high prevalence (56.0\%) of underweight. These results were in accordance with the results of the present study. This may be due to the same economic background and similar cultural preferences. The prevalence of underweight in this study was high compared with the previous study conducted by Kritika et al. in 2014 in a rural community of India [17]. A multi-dimensional cross-sectional study of community-based elderly people aged 60 years and over was conducted in a rural area in Bangladesh, and the study showed that about 50 (49.7\%) of the participants had a BMI $<18.5 \mathrm{~kg} \cdot \mathrm{m}^{-2}$ [18]. These results were consistent with the results of the present study. This may be due to similar demographic characteristics and equal societal predilections. Another study by Yadap et al. [19] found that $14.6 \%$ were underweight, which is 3.5 times lower than the present findings $(48.3 \%)$. This variation may be due to the lack of economic independence and their personal lifestyle.

In an attempt to study the relationship of different socioeconomic variables with nutritional status, a significant relationship was observed between age groups and nutritional status. Older age significantly associated with lower BMI that is underweight in our population. A similar observation between the age group and nutritional status was also made in the studies done by Faruque et al. [20] and Cuervo et al. [21]. In studies conducted in a rural population of Tamil Nadu, it appeared that elderly people above 80 years of age were also significantly associated with poor nutritional status [22]. Using anthropometric measures, a study from rural Malawi demonstrated that among its elderly, underweight is a significant problem and more intense in those $\geq 80$ years of age [23]. The results from the present study also indicate that underweight was more intense in very old elderly.

The present study revealed that the relationship between gender and nutritional status was statistically significant. Men were more underweight compared to women, whereas women were more overweight than men. Some potential explanations for these gender differences include physiological differences between males and females, used of contraceptive methods and decreased outdoor physical activity levels among females $[15,17]$. Earlier studies were done by Vedantam et al. [22], Chilima et al. [23] and Aliabadi et al. [24], who also found a significant association between females and nutritional status, where females were more overweight compared to males. Donini et al. [25] stated that females were significantly more underweight compared to males, which is inconsistent with the current study result. This may be due to a different socio-economic background and diverse cultural preferences. A cross-sectional study by Agarwalla et al. [26] also observed that elderly people, particularly females, were more underweight compared to males. The above findings were dissimilar with the current study findings, and these discrepancies are often due to reduced appetite and decreased food intake in those of advanced age, where females are more accustomed to chewing beetle-nut, as well as different smokeless and smoking tobacco. These may interfere with their eating habits, as well as interfere with their appetite.

In the present study, the relationship between marital status and nutritional status was not significant. The relationship between marital status and nutritional status was not confirmed by the results reported by Boulos et al. in Lebanon [27] and Saikia and Mahanta in Guwahati, Assam [28], but it was inconsistent with the results by Aliabadi et al. [24]. 
The current study findings indicate that the level of education had no significant influence on the nutritional status of the elderly. Kabir et al. conducted a multi-dimensional crosssectional study in Bangladesh among 850 randomly selected elderly individuals, and the study showed that the level of education was directly associated with nutritional status [13]. Another prospective associated study undertaken in the Razavi Khorasan Province, Iran, reconfirmed that nutritional status was associated with education [24]. There was an inconsistency between the above findings and the present study results. These inconsistencies may be due to the lower level of education of the study participants and are possibly associated with lower income and an unhealthy lifestyle, which in turn bring about a poorer nutritional status in these elderly.

An analysis of the relationship of family income with nutritional status revealed no significant relationship, which was inconsistent with studies done by Kabir et al. [18], Agarwalla, et al. [26] and Aliabadi et al. [24]. These discrepancies are due to the different socio-economic background and cultural variation of the study participants. The current study findings also indicate that employment status, family types and living arrangement had no significant influences on the nutritional status of the elderly. A similar association was found in the study by Sharma [29]. A community-based cross-sectional study conducted by Ananthesh et al. [30] found that employment status and family type were not significantly associated with the nutritional status of the elderly, which is similar to the findings of the present study. The present study also revealed that living arrangements had no significant influence on the nutritional status of the elderly. Similar findings were present in the studies by Donini et al. [25] and Boscattoa et al. [31]. The present study findings were inconsistent with the findings of Aliabadi et al. [24], where employment status and type of living were significantly associated with the nutritional status of the elderly. These variations may be due to the different socio-economic background and diversified cultural preferences.

\section{Conclusions}

This study addressed the nutritional status of rural elderly persons in different socio-economic parameters and revealed that underweight is associated with increasing age and gender. In conclusion, it was determined that the Bangladeshi elderly population demonstrated a vulnerable nutritional status, because of the high prevalence of underweight. Therefore, both good health and good nutritional status are essential for elderly persons to be functionally active. From the public health point of view, there is a need to raise awareness among the elderly regarding their nutrition.

Source of funding: This work was funded by the author's own resources. Conflict of interest: The author declares no conflict of interests.

\section{References}

1. United Nations. Department of Economic and Social Affairs, Population Division. World Population Ageing 2013. New York: United Nations; 2013.

2. United Nations. Department of Economic and Social Affairs, Population Division. World Population Prospects. The 2002 Revision. New York: United Nations; 2003.

3. Streatfield P, Karar ZA. Population challenges for Bangladesh in the coming decades. J Health Popul Nutr 2008; $26: 261-272$.

4. Kabir ZN. The emerging elderly population in Bangladesh: aspects of their health and social situation, in Division of Geriatric Medicine and Department of Public Health Sciences. Stockholm: Karolinska Institute; 2001.

5. Schroeder DG. Malnutrition, in nutrition and health in developing countries. Semba R.D. and Bloem M.W., eds. Humana Press Inc: Totowa, New Jersey; 2001.

6. Locher JL, Ritchie CS, Roth DL, et al. Social isolation, support and capital and nutritional risk in an older sample: ethnic and gender differences. Soc Sci Med 2005; 60: 747-761.

7. Pirlich M, Schutz T, Kemps M, et al. Social risk factors for hospital malnutrition. Nutrition 2005; 21: 295-300.

8. Barreto SM, Passos VMA, Lima-Costa MF. Obesity and underweight among Brazilian elderly. The Bambuí Health and Aging Study. Cad Saúde Pública 2003; 19: 605-612.

9. Coqueiro RS, Barbosa AR, Borgatto AF. Nutritional status, health conditions, and socio-demographic factors in the elderly of Havana, Cuba: data from SABE survey. J Nutr Health Aging 2010; 14: 803-808.

10. Ferreira LS, Amaral TF, Marucci MFN, et al. Undernutrition as a major risk factor for death among older Brazilian adults in the community-dwelling setting: SABE survey. Nutrition 2011; 27: 1017-1022.

11. Islam MZ, Lamberg-Allardt C, Karkkanen M, et al. Dietary calcium intake in premenopausal Bangladeshi women: do socio-economic or physiological factors play a role? Eur J Clin Nutr 2003; 57: 674-680.

12. Pryer JA, Rogers $S$, Rahman A. The epidemiology of good nutritional status among children from a population with a high prevalence of malnutrition. Public Health Nutr 2003; 7: 311-317.

13. WHO. Obesity: preventing and managing the global epidemic. Report of a WHO Consultation. WHO Technical Report Series 894 . Geneva: World Health Organization; 2000.

14. Yasmeen F, Badrunnahar B. Nature and extent of malnutrition among the elderly attending an urban geriatric centre. JOPSOM 2002; 21(1): 43-49.

15. Flora MS. Ageing: a growing challenge. Bangladesh Medical Journal 2011; 40(3): 48-51.

16. Alam MA, Rahman M, Flora MS, et al. Household food security and nutritional status of rural elderly. Bangladesh Medical Journal 2011; 40(3): 8-11.

17. Kritika, DeepShikha, Semwal J, et al. Nutritional status and associated comorbidities among the elderly in Doiwala block, Dehradun. Indian Journal of Community Health 2014; 26(2): 197-203.

18. Kabir ZN, Ferdous T, Cederholm T, et al. Mini Nutritional Assessment of rural elderly people in Bangladesh: the impact of demographic, socio-economic and health factors. Public Health Nutr 2006; 9: 968-974.

19. Yadap N, Rabindra R, Sharma S, et al. Dietary habits and nutritional status of elderly living in urban areas of Allahabad district. Indian J Pre Soc Med 2012; 43(1): 84-86.

20. Faruque ASG, Khan Al, Roy $\mathrm{CN}$, et al. Anthropometric characteristics of elderly people: observations at a large diarrheal hospital in Dhaka, Bangladesh. Southeast Asian J Trop Med Public Health 2006; 37: 784-91.

21. Cuervo M, García A, Ansorena D, et al. Nutritional assessment interpretation on 22,007 Spanish community dwelling elders through the Mini Nutritional Assessment test. Public Health Nutr 2009; 12(1): 82-90. 
22. Vedantam A, Subramanian V, Rao NV. Malnutrition in free-living elderly in rural south India: prevalence and risk factor. Public Health Nutr 2009; 13(9): 1328-1332.

23. Chilima DM, Ismail SJ. Anthropometric characteristics of older people in rural Malawi. Eur J Clin Nutr 1998; 52: 643-649.

24. Aliabadi M, Kimiagar M, Ghayour-Mobarhan M, et al. Prevalence of malnutrition in free living elderly people in Iran: a cross-sectional study. Asia Pac J Clin Nutr 2008; 7(2): 285-289.

25. Donini LM, Scardella P, Piombo L, et al. Malnutrition in elderly: social and economic determinants. J Nutr Health Aging 2013; 17: 9-15.

26. Agarwalla R, Saikia AM, Baruah R, et al. Assessment of the nutritional status of the elderly and its correlates. J Family Community Med 2015; 22(1): 39-43.

27. Boulos C, Salameh P, Barberger-Gateau P. The AMEL study, a cross sectional population-based survey on aging and malnutrition in 1200 elderly Lebanese living in rural settings: protocol and sample characteristics. BMC Public Health 2013; 12(13): 573.

28. Saikia A, Mahanta N. A study on nutritional status of elderly in terms of body mass index in Urban Slums of Guwahati City. J Indian Acad Geriatr 2013; 9: 11-14.

29. Sharma R. Relationship between Mini Nutritional Assessment Scores and Socioeconomic Status of the Elderly. J Community Nutr Health 2012; 1(2): 32-42.

30. Ananthesh BG, Bathija GV, Bant DD. A community based cross-sectional study to assess malnutrition among elderly population residing in urban and rural areas of a district in Karnataka, India. Int J Community Med Public Health 2017; 4(1): 51-58.

31. Boscattoa EC, Duarteb MFS, Coqueiroc RS, et al. Nutritional status in the oldest elderly and associated factors. Rev Assoc Med Bras 2013; 59(1): 40-47.

Tables: 3

Figures: 0

References: 31

Received: 14.11.2016

Revised: 02.03.2017

Accepted: 04.03.2017

Address for correspondence:

Sumon Chandra Debnath, MPH

District Trainer

National Institute of Preventive and Social Medicine (NIPSOM)

Mohakhali, Dhaka-1212

Bangladesh

Mobile: +8801710385416

E-mail: sumonphysio@gmail.com 